\title{
EL USO COMPARTIDO DE LA EMOCIÓN: ¿PORQUÉ NECESITAMOS COMPARTIR LAS EMOCIONES? ${ }^{1}$
}

\section{SHARED USE OF EMOTION: WHY DO WE NEED TO SHARE THE EMOTIONS?}

\author{
Francisco Martínez Sánchez \\ Universidad de Murcia, España
}

Palabras clave: Compartimiento social de las emociones, emociones, 11 M terrorismo.

Keywords: Social sharing of emotions, emotions, 11M terrist atack.

En primer lugar quería agradecer a la Universidad Católica de Uruguay y a mis compañeros, los Profesores de la Facultad de Psicología, su invitación a estar con ustedes en este acto.

La emoción tiene una dimensión comunicativa, poco estudiada a lo largo de la historia de la ciencia. Será éste el tema principal que desarrollaré en esta conferencia: ¿porqué y cómo compartimos socialmente nuestras emociones? ¿qué efectos tiene el uso social compartido de las emociones?

La inmensa mayoría de las sociedades occidentales acepta universalmente que la expresión verbal de la emoción es adaptativa y que, al compartir nuestras emociones con los demás, se produce un alivio en el sujeto. De hecho, al preguntar a un grupo de más de mil personas: ¿cree usted que expresar verbalmente las emociones produce un alivio emocional?, aproximadamente

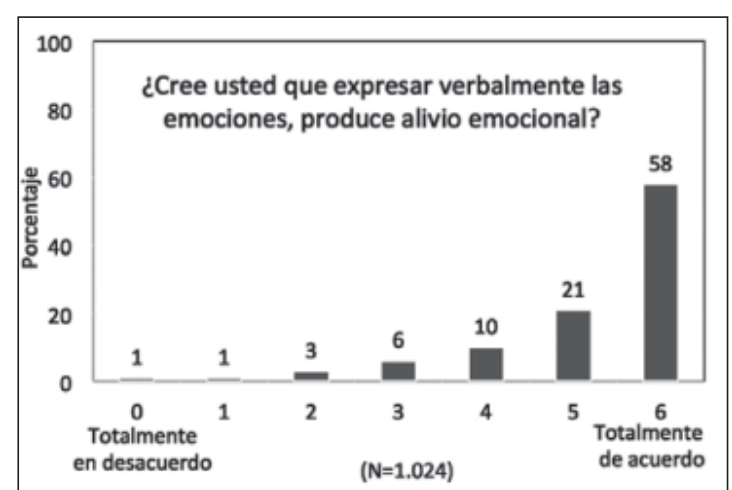

Figura 1. Porcentaje de acuerdo con la afirmación: ¿Cree usted que expresar verbalmente las emociones produce alivio emocional?; $n=1.024$ sujetos (Zech, 2000). el $58 \%$ de ellas afirma que está totalmente de acuerdo con esta afirmación (Figura 1).

Estos datos ponen de manifiesto que todos aceptamos que este proceso es un fenómeno adaptativo y beneficioso. El proceso es especialmente evidente cuando nos enfrentamos a acontecimientos vitales relevantes. Así, cuando vivimos una situación emocionalmente intensa, con frecuencia la rumiamos una y otra vez, rememorándola constantemente. Por ejemplo, si estudiamos cuál es el patrón de rumiación de una persona después de la muerte de un familiar cercano vemos como el $100 \%$ de las personas, 10 días después de su muerte, siguen rumiándolo, analizando lo que ocurrió y sus repercusiones; ese patrón va disminuyendo de manera muy lenta, ya que al mes el $91 \%$ de las personas siguen rememorándolo y tres meses después casi $88 \%$ de las personas continúan haciéndolo (Figura 2).

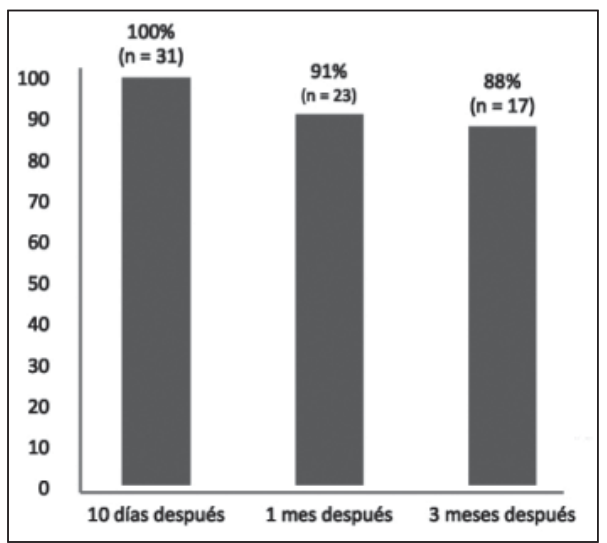

Figura 2. Evolución de la rumiación tras la muerte de un familiar cercano (Rimé et al. 1998).

Correspondencia: Francisco Martínez Sánchez. Departamento de Psicología Básica y Metodología. Facultad de Psicología. Universidad de Murcia. España. Correo Electrónico: franms@um.es. 
Vemos que esa rumiación es un proceso que ocurre de manera habitual en todos nosotros y que, además, se da ante muchas circunstancias, no sólo ante acontecimientos negativos, sino también ante los positivos, siempre que tengan una relevancia emocional intensa. Por ejemplo, para los estudiantes de medicina de primer año la primera disección supone un acontecimiento muy importante, significa entrar en contacto con los cadáveres y es algo que están esperando, y son conscientes de que les supondrá un impacto emocional. Cuando les preguntamos, ¿cuánto tiempo ha rumiado después de haber hecho la primera disección?, una semana después el $65 \%$ sigue rememorándola intensamente, hasta desparecer 3 meses después. Obviamente, los procesos adaptativos hacen que la frecuencia de la rumiación descienda paulatinamente de forma natural.

La gente rumia tanto las emociones positivas como negativas; esto es, tanto las cosas que nos pasan que nos inducen estados emocionales de bienestar como de malestar. Un tanto por ciento muy alto de las personas afirman que rememoran estos sucesos muy a menudo (Figura 3).

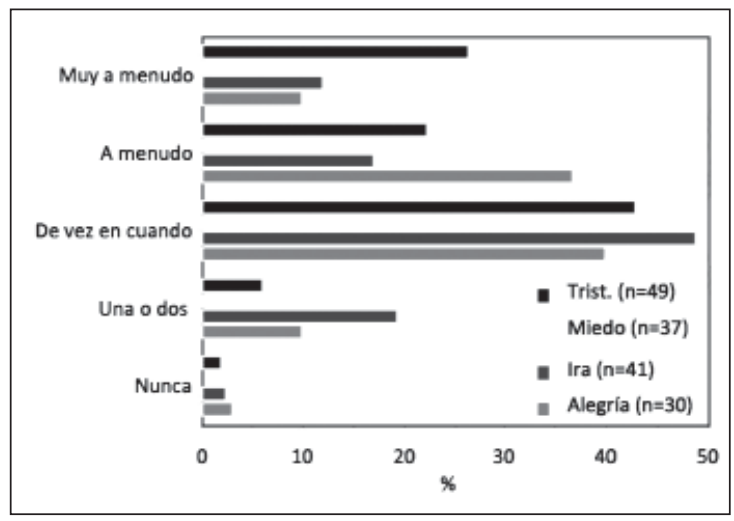

Figura 3. Frecuencia de rumiación de varias emociones (Rimé et al. 1998).

Si nos preguntamos ¿qué emociones se rumian con más frecuencia?, vemos cómo la tristeza es la más frecuente. Si recuerdan algún episodio de tristeza que hayan vivido, comprobarán la persistencia en el tiempo de este proceso. Sabemos que el impacto de los sucesos negativos es mucho más duradero que el de los positivos. Por cuanto, los acontecimientos negativos causan en nosotros un mayor impacto, son más persistentes en nuestro pensamiento y en la memoria, son más intrusivos y nos afectan de forma más intensa y prolongada en el tiempo.

Veamos, como ejemplo, dos acontecimientos que son paradigmáticos, porque nos permiten entender cómo reaccionamos normalmente ante un acontecimiento importante. El primero de ellos es, tal vez los más jóvenes no lo recuerden, me refiero al un devastador terremoto que se produjo en el área de la bahía de San Francisco en 1989; el sísmo duró sólo 15 segundos, causó 63 muertos, hirió a 3.757 personas y produjo entre 8.000 y 12.000 damnificados. Recordarán que hace sólo 4 días, el 11 de Mayo, en España hubo también un terremoto, en Lorca, sin embargo las consecuencias han sido mucho menores, ha habido 9 muertos.

Nos interesa los efectos del terremoto de San Francisco, porque es un acontecimiento de fuerte carga emocional, que afectó a un gran número de personas, de tal forma que nos va a permitir estudiar cómo la gente comparte sus emociones en situaciones traumáticas. Una semana después del acontecimiento, los profesores Pennebaker y Harber diseñaron una investigación para estudiar a grupos muy grandes de personas que habían vivido esa situación; realizaron un estudio longitudinal en el que, a lo largo de 16 semanas podían ver cómo la gente iba compartiendo sus emociones, para poder estudiar el patrón temporal de compartimiento. La pregunta que se le hacía a las personas era ¿durante cuánto tiempo ha hablado las últimas 24 horas del terremoto?(Figura 4).

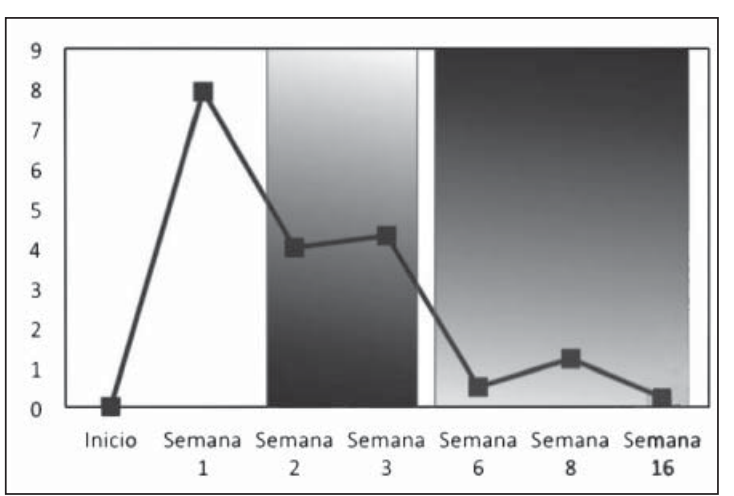

Figura 4. Frecuencia con la que las personas habían hablado con otros del terremoto, durante las 24 horas previas a la toma de datos. 
Los resultados mostraron que desde la primera semana, la gente habló durante muchísimo tiempo, y con muchas personas, del terremoto, pero conforme pasaban las semanas el tiempo que la gente empleaba en hablar de él fue decreciendo. Este fenómeno es adaptativo, el tiempo va haciendo su labor para ayudarnos a recuperarnos de acontecimientos traumáticos, aunque no siempre es así, ya que en ocasiones causa trastornos muy duraderos e intensos.

Pasado el impacto inicial de las primeras semanas, llega un momento en que nos habituamos y cada vez hablamos menos. Lo interesante de este patrón, es que se produce una primera caída que se corresponde con una disminución del número de veces que habían hablado. Si inicialmente hablaron en ocho ocasiones en promedio a partir de la segunda y tercera semana se redujo de manera significativa, además, este efecto de reducción del compartimiento es aún más intenso a partir de la sexta semana. Los sujetos manifestaban sentir ganas de hablar, pero ponían trabas cuando alguien les suscitaba una conversación que tuviera el terremoto como tema. Este es un aspecto importante: "yo quiero compartir pero no deseo que lo compartan tanto conmigo". ¿Por qué?, de alguna manera, la gente percibe que cuando están compartiendo, el interlocutor le está induciendo un estado de malestar puesto que han de revivir la situación. Además, en estas semanas empezaron a aparecer muchos indicadores somáticos de malestar. De tal manera que la gente acudía al médico de familia, con síntomas que sabemos que están ligados a la activación emocional, tales como la dificultad para conciliar el sueño o los dolores de cabeza.

Otro acontecimiento, aunque diferente, que también nos sirve como ejemplo, es la Guerra del Golfo. Recordarán que ésta se produjo en 1991, y estuvo causada por que Irak invadió el Emirato de Kuwait, un país muy pequeño pero que, como sospecharán, tiene muchísimo petróleo. Se formó una coalición internacional liderada por los Estados Unidos y compuesta por 31 naciones, que inició una guerra para liberar el pequeño emirato. Este conflicto tiene mucho interés en el estudio del compartimiento social de la emoción puesto que ocurrió en un país lejano, a muchos miles de kilómetros de Estados Unidos; además, "sólo" murieron 318 soldados de la coalición de los 450 mil que participaron, mientras que se estima (la cifra no se sabe con certeza) que murieron entre 25 y 30 mil iraquíes.

Me interesa especialmente para mostrar cómo algo que ocurre muy lejos de nosotros, también nos afecta y nos provoca reacciones emocionales. La afectación emocional estuvo provocada porque fue una guerra televisada, que hizo durante todo el día podíamos ver imágenes impactantes, no sólo de muertos y destrucción, sino también del desastre ecológico que produjo el que los iraquíes prendieran fuego a muchos campos petroleros. Como saben, la guerra se resolvió en muy poco tiempo con una victoria de la coalición aliada.

Se realizó un estudio en el que se preguntó a la gente en Estados Unidos, ¿cuántas veces habló las últimas 24 horas sobre la guerra?, ¿con cuántas personas? y ¿durante cuánto tiempo?. Los resultados mostraron un patrón muy similar al que se obtuvo en el estudio anterior del terremoto de Los Ángeles, del que ya hemos hablado. Inicialmente se habló diariamente con 14 personas de media, pero a lo largo de las semanas la frecuencia, la intensidad y la duración del compartimiento se fue reduciendo paulatinamente; el efecto es similar al anteriormente descrito, aun siendo acontecimientos muy distintos. En este caso los afectados eran personas que no habían estado directamente en la guerra, pero al haberla vivido a través de la televisión les había inducido una respuesta emocional. Como vemos, el patrón se repite y nos permite concluir que en situaciones traumáticas que afectan a grandes colectividades, tanto si el sujeto esta directamente implicado, como si se siente implicado vicariamente (indirectamente), va a dar una respuesta emocional, y ésta tiene una dimensión comunicativa que se manifiesta hablando muchas veces, con muchas personas y durante mucho tiempo; más tarde, ese efecto va disminuyendo, hasta recobrar la situación anterior a que ocurriera el hecho traumático.

Esta serie de acontecimientos y otras muchas razones justifican que el Profesor Bernard Rimè, de la Universidad de Lovaina, en Bélgica, formulara el concepto de compartimiento social de la emoción. Éste sostiene que la gente desea y necesita compartir con los demás sus emociones; en otras palabras: cuando vivimos 
algún acontecimiento emocionalmente importante para nosotros, tenemos la necesidad de compartirlo con los demás.

Así, por ejemplo, cuando preguntamos a un grupo de personas ¿cuántas veces has compartido con otros lo que te ocurrió?, casi el $70 \%$ afirma que lo ha hablado con 6 o más personas; obviamente nos referimos a acontecimientos que tienen una carga emocional fuerte, ya que no solemos compartir sucesos triviales o que carecen de relevancia (Figura 5). Este hecho se produce en respuesta a acontecimientos negativos, pero también con sucesos positivos. Así, por ejemplo, si le preguntamos a un grupo de madres primerizas, ¿con cuántas personas ha hablado del nacimiento de su hijo?, el patrón de respuestas que obtenemos es el similar. Desde la segunda semana tras el parto, el número de personas con las que se habla de este hecho va disminuyendo progresivamente. Como ven, también tenemos la necesidad de compartir las emociones positivas con los demás (Figura 6).

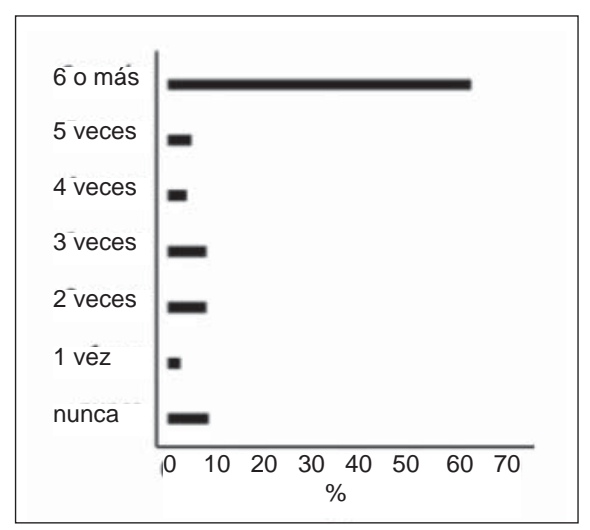

Figura 5. Frecuencia de respuestas a la pregunta: “¿Cuántas veces ha hablado sobre un acontecimiento emocional reciente?” Baruffol, Gisle y Rimé (1998)

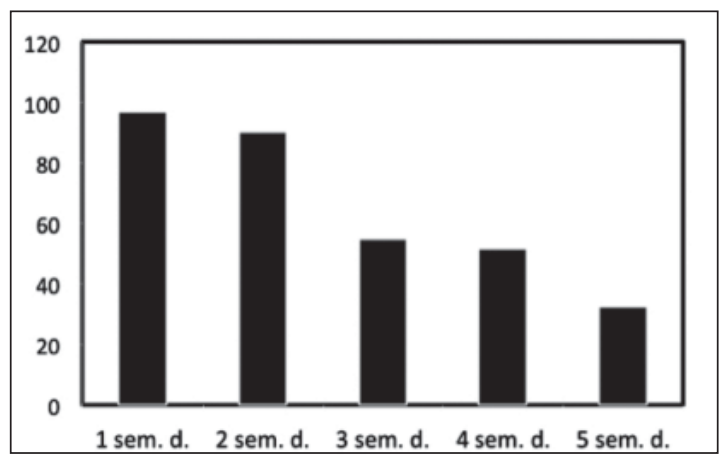

Figura 6. Frecuencia de respuestas a la pregunta: “¿Con cuantas personas ha hablado usted del nacimiento de su hijo?”, en madres primerizas.
La intensidad de la emoción que sentimos inicialmente es un factor relevante para explicar el compartimiento. En una investigación se pretendía verificar la hipótesis que sostiene que cuanto más intenso es un acontecimiento emocional y, por tanto, con mayor intensidad lo hemos vivido, en mayor medida los compartiremos posteriormente. El procedimiento consistió en narrar tres sucesos emocionales con distinta carga; a un grupo, se le contaba algo trivial, es decir, sin carga emocional; a otro con una intensidad media y a un tercer grupo se le contó un suceso con alta carga emocional. ¿Compartirían con más personas, los que han recibido la narración con un contenido emocional más intenso?. Como sospechan así es, se comparte más veces y con más personas cuanto más intensa es la respuesta emocional que nos provoca ese suceso (Figura 7).

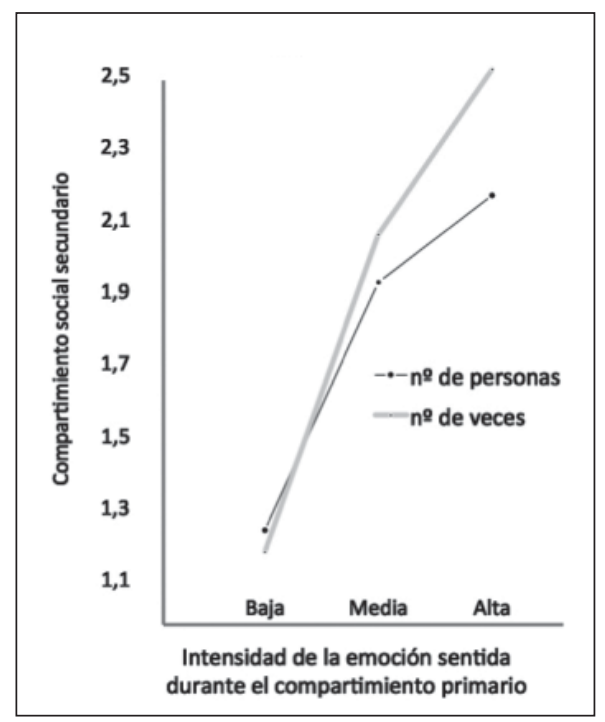

Figura 7. Relación entre intensidad y grado de compartimiento de una emoción. Christophe y Rimé (1997).

Como ven, parece existir una relación lineal directa entre intensidad del acontecimiento vivido y el grado en que lo compartimos, pero no es así. Compartimos más los acontecimientos de intensidad moderada y alta, pero no los de intensidad extrema, ni tampoco los de baja intensidad normalmente.

Veamos un ejemplo que demuestra que el grado de compartimiento está relacionado con la intensidad de la respuesta emocional dada por el sujeto. Se proyectaban tres tipos de pe- 
lículas distintas a tres grupos de sujetos. Uno de los grupos veía un documental de National Geographic, en que aparecían paisajes muy atractivos. Un segundo grupo vio un documental en que se veían animales en actitudes muy violentas; finalmente, un tercer grupo observó imágenes de alto contenido violento entre humanos. Interesaba básicamente saber la respuesta que suscitaban en los sujetos ver, bien ese paisaje bucólico, que no tenía valor emocional alguno, así como las escenas de violencia animal y violencia humana. Los resultados mostraron que cuanto más intensa emocionalmente era la película, con más gente se compartía; los resultados fueron especialmente evidentes en el grupo que vio la película de fuerte carga violenta entre hombres. En suma: cuanto más intensa es la reacción con que vivimos una situación, mayor necesidad tenemos de compartirla posteriormente (Figura 8).

Normalmente el proceso de compartimiento se hace el mismo día en que sucedió el hecho. En la mayoría de las ocasiones, las personas sienten la necesidad, una suerte de emergencia casi instantánea, de compartirlo. Esto es, normalmente no pueden postergarlo para otro día, sino que necesitan compartirlo inmediatamente si el acontecimiento tiene un fuerte carácter emocional. Piensen ustedes en alguna circunstancia vital intensa que les haya acaecido y podrán recordar la necesidad que han tenido de compartirla casi inmediatamente. Sabemos que en el $60 \%$ de los ocasiones aproximadamente se comparte el mismo día, tanto las emociones positivas como las negativas. Pero esto no ocurre así cuando sentimos dos emociones: la vergüenza y la culpa. La vergüenza implica un juicio negativo que los otros pueden hacer sobre nuestra conducta; por su parte, la culpa está ligada a la conciencia personal de haber transgredido una norma social que tenemos interiorizada. Si nosotros mismos nos sentimos mal (y experimentamos culpabilidad o vergüenza), no deseamos que otra persona lo sepa, porque creeremos estar sujetos también a su juicio y posible reprobación, por este motivo no las compartimos y habitualmente las guardamos para nosotros mismos.

Pero, ¿cómo se produce el proceso de compartimiento?. Pensemos en una persona que acaba de recibir una noticia que tiene una fuerte carga emocional, esa noticia va a inducir necesariamente la necesidad de compartirla. De esta forma se inicia un proceso de orden creciente por el una persona $(A)$, que ha vivido la experiencia emocional, necesita compartirla con otra (B). Como ya hemos visto, este proceso se realiza de forma casi inmediata, en la mayoría de los casos el mismo día. Pensemos ahora en el interlocutor (B) a quien hemos hecho la confidencia: al compartir la vivencia emocional con él, esta persona ha vivido empáticamente el proceso, por tanto, en esta segunda persona (B) se generará también un estado de activación emocional, de menor intensidad de la que experimentó el protagonista del suceso $(A)$, pero también cargado de vivencia emocional. Tanto más intensa es la respuesta emocional suscitada en las segunda persona (B), tanto mayor es el grado de necesidad de volver a compartirlo

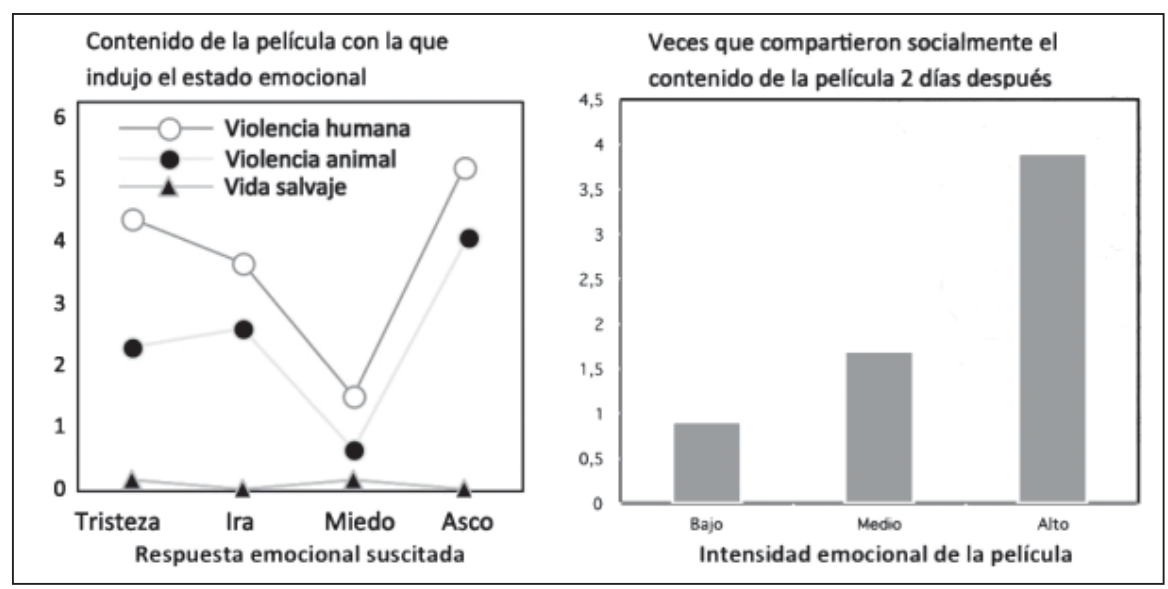

Figura 8. Relación entre intensidad emocional y grado de compartimiento ante tres tipos de estímulos con distinta intensidad emocional. Luminet et al. (2000) 
con otras personas; pensemos en "una patata caliente", que necesitamos apartar de nuestras manos para aliviar el malestar que nos produce. Lógicamente, el sujeto que vivió primariamente el hecho (A) sentirá alivio al compartirlo con el segundo (B) pero, a su vez, inducirá malestar al segundo.

Podríamos preguntarnos: ¿necesita el sujeto $B$ (quien recibió la confidencia de A), compartirlo con otro (C)? y a su vez ¿precisa el sujeto $C$ compartirlo con un nuevo sujeto de su confianza (D), prolongándose en compartimientos de orden creciente? (Figura 9).

Como habrán sospechado la respuesta es afirmativa. El sujeto B precisa compartir en el $66 \%$ de los casos con otros (C); es curioso que el $85 \%$ de los sujetos que están en el nivel B afirman que "eran muy amigos" de A y, a pesar de ello, lo compartieron con un nuevo sujeto (C). Esta evidencia contradice la creencia que sostiene que cuando nos hacen una confidencia no la diseminamos, guardándola para nosotros, ya que la discreción que impone la amistad supuestamente salvaguarda su difusión.
¿No sé si están pesando ya...? si, por sus expresiones ya veo que si: cuando contamos algo importante a alguien, al menos el $66 \%$ de las personas vuelven a compartirlo (a contarlo, en definitiva) a una tercera persona. Es más, el $53 \%$ de las personas afirma que lo ha contado a dos o más personas. De tal manera que el acontecimiento inicial se va difundiendo en círculos de amplitud creciente. Los compartimientos de orden terciario son muy frecuentes, esto es: una persona vive un acontecimiento emocional (A), lo comparte con otro (B), -compartimiento de orden primario-, ese otro lo comparte con el siguiente (C), - orden secundario- y éste, a su vez, habitualmente lo comparte con otro más (D). Recuerden la comparación con la "patata caliente"; lógicamente, conforme se producen estos procesos esa "patata" va disminuyendo paulatinamente el calor residual conforme pasa de mano en mano (de A a B y posteriormente de $B$ a $C y$, más tarde, de $C$ a D). Finalmente el suceso va perdiendo carga emocional (se enfriaría totalmente, siguiendo el símil de la patata) y cesarían los procesos de diseminación y compartimiento (Figura 10).

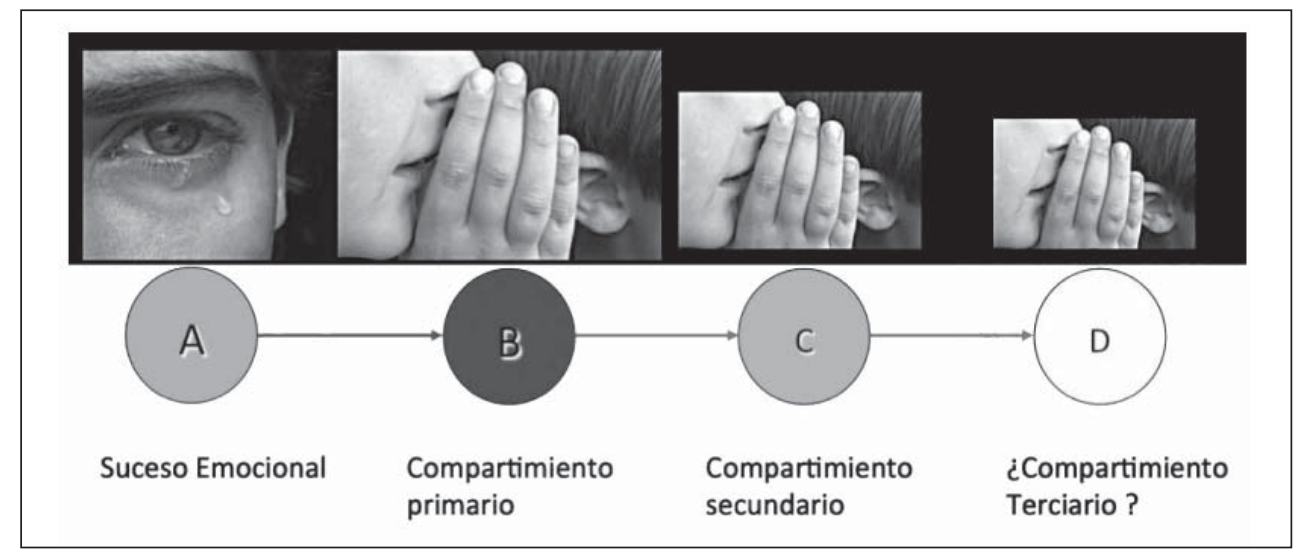

Figura 9. Compartimiento social de la emoción de orden primario, secundario y terciario

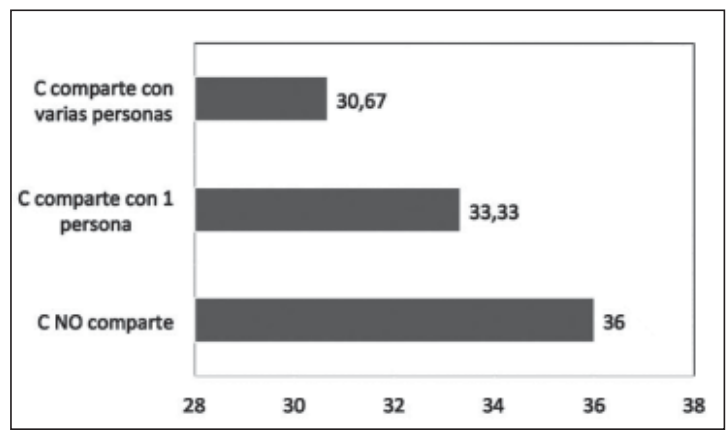

Figura 10. Frecuencia de compartimiento de uso terciario (Christophe, 1997) 
Esas personas de la que hablamos (C) afirman compartir con varias personas en el 30\% de las ocasiones, un 33\% dice que comparte con una sola persona y el $36 \%$ no lo comparten.

Si yo les preguntara a ustedes si comparten con los demás sus emociones ¿qué me responderían?; les haré una pregunta aún más comprometedora ¿ustedes comparten con una tercera persona las confidencias emocionales que les han hecho?. Aunque me dijeran que no, no les creería.

Numerosas investigaciones demuestran que este proceso tiene un carácter casi universal, si bien también es cierto que unos pueblos comparten más que otros. Las sociedades occidentales expresan más frecuente e intensamente las emociones, al contrario que las sociedades orientales, quienes las expresan de forma más contenida y controlada. Las sociedades latinas (España, Italia, Francia, etc.) y anglosajona fomentan la expresión emocional y, por tanto, también su compartimiento. Los patrones de expresión y compartimiento en la sociedad uruguaya, por los datos que hemos obtenido en una investigación realizada conjuntamente con la Dra. María Luisa Blanco, profesora de esta Universidad, demuestran que el proceso de compartimiento es muy similar al que se produce en España, si bien de forma más atenuada.

El resultado del uso compartido de la emoción, articulado mediante esos procesos de orden creciente (primario, secundario y terciario), nos permiten afirmar que, cuando una persona ha vivido una experiencia emocional intensa, entre 50 y 60 personas de su comunidad tienen noticias de ella a las pocas horas de producirse el hecho. Repito siempre que el acontecimiento tenga relevancia emocional, de no ser así no se comparte. ¿Estos datos implican que, aunque nosotros (A) pidamos a nuestro interlocutor (B) que no revele la confidencia, lo compartirá con una cercera persona (C)?. La respuesta es afirmativa, no siempre, pero si en la mayoría de las ocasiones. Aún cuando digamos a nuestro confidente (B): "por favor, no cuentes esto a nadie"; en ese momento lo estamos incitando a que lo disemine y comparta. Tanta mayor relevancia tenga el suceso emocional que vivió $A$, tanto más lo diseminará a $B, C, D$ y éstos a su vez, a otros sujetos.

Harber y Cohen estudiaron en 2005 un grupo formado por 33 estudiantes de medicina que asistieron a la morgue de un hospital. Supondrán que esta visita provoca reacciones emocionales en todos, especialmente la primera vez que se realiza. Se estudió cómo reaccionaron los estudiantes y, especialmente, cómo compartieron socialmente esa experiencia (Tabla 1 y 2 ).

En este ejemplo se cumple fielmente el proceso que he descrito, por cuanto durante la primera semana, el compartimiento (entre los propios estudiantes) fue de 6 contactos de media por persona; es decir, cada uno de los 33 sujetos habló con 6 personas sobre el tema, no con terceras personas sino entre los propios estudiantes. A su vez, si analizamos con cuantos amigos de estos estudiantes,

Tabla 1.

Patrones de compartimiento social de estudiantes de medicina tras la visita a la morgue.

\begin{tabular}{lccc}
\cline { 2 - 4 } & $\begin{array}{c}\text { Primario } \\
\text { (entre los } \\
\text { estudiantes) } \\
(n=33)\end{array}$ & $\begin{array}{c}\text { Secundario } \\
\text { (los amigos de los } \\
\text { estudiantes) } \\
(n=32)\end{array}$ & $\begin{array}{c}\text { Terciario } \\
\text { (los amigos de los amigos } \\
\text { de los estudiantes) } \\
(n=27)\end{array}$ \\
\hline № (tasa de compartimiento) & $32.00(97 \%)$ & $27.00(82 \%)$ & $16.00(48 \%)$ \\
Media de contactos por sujeto & $6.21(4.06)$ & $0.46(1.21)$ & $1.26(1.20)$ \\
NNo Total de contactos a este nivel & 205 & 299 & 377 \\
\hline
\end{tabular}

Tabla 2.

Relación entre el nivel de compartimiento y la reacción emocional suscitada

\begin{tabular}{lccc}
\cline { 2 - 4 } & $\begin{array}{c}\text { Primario } \\
\text { (entre los } \\
\text { estudiantes) } \\
(n=33)\end{array}$ & $\begin{array}{c}\text { Secundario } \\
\text { (los amigos de los } \\
\text { estudiantes) } \\
(n=32)\end{array}$ & $\begin{array}{c}\text { Terciario } \\
\text { (los amigos de los amigos } \\
\text { de los estudiantes) } \\
(n=27)\end{array}$ \\
\hline Intensidad de la reacción emocional & $0.73^{* *}$ & 0.24 & $0.46^{*}$ \\
Grado de compartimiento & & $0.56^{* *}$ & $0.61^{* *}$ \\
\hline
\end{tabular}


se hablo del tema, vemos que el número de contactos se amplió sensiblemente ya que el $82 \%$ de ellos lo comentaron con otras personas y, a su vez, el $48 \%$ de ellos lo volvieron a comentar con otros. En su conjunto, 881 personas tuvieron noticia del acontecimiento en sólo 3 días, irecordemos que, inicialmente, sólo 33 personas visitaron la morgue!.

Tanto más intensamente vivieron los 33 estudiantes la visita, tanto más la compartieron; en otras palabras: el nivel de compartimiento depende de la intensidad emocional con la que vivieron el hecho inicialmente. De igual modo, el compartimiento secundario y terciario también está determinado por este factor, así por ejemplo, los amigos de los estudiantes (compartimiento secundario) que dieron una reacción emocional más intensa, fueron quienes más lo difundieron a su vez entre sus amigos.

¿Compartimos igual en función de la edad? No, claro que no. Por ejemplo cuando estudiamos cómo comparten los niños más pequeños de entre 6 y 8 años y entre 8 y 12, aparece un patrón muy específico que muestra que éstos comparten preferentemente con sus padres, sobre todo hasta los 12 años. En la adolescencia el patrón cambia y hace que se comparta más con el mejor amigo, pero ya no con los padres. Entre los adultos ¿comparten por igual hombres y mujeres?. La respuesta es sencilla, todos ustedes saben que la mujer tiene una red afectiva y de contactos más extensa que el hombre. Los hombres suelen compartir preferentemente con la pareja, mientras que la mujer lo hace más frecuentemente con su familia (me refiero a la familia de la mujer, sus padres, hermanos, etc.) más que con el marido. Por sus expresiones veo que no les estoy descubriendo nada nuevo (Figura 11).

La mujer comparte preferentemente con su familia y amigas en mayor media que el hombre. El patrón de compartimiento se va incrementando a lo largo de la vida en ambos sexos; esto es, la mujer comparte paulatinamente más desde la infancia a la adolescencia, la edad adulta y la vejez que el hombre. Este efecto se produce de la misma forma en todas las edades, con pequeños cambios, pero siempre la mujer comparte con más personas y más intensamente.

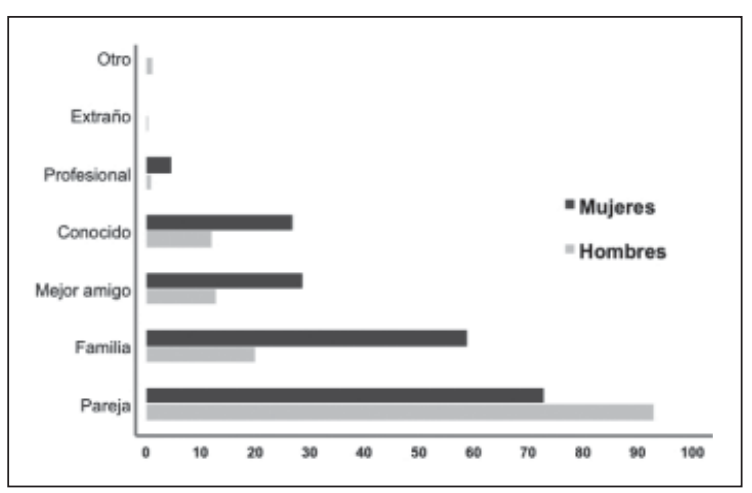

Figura 11. Patrón de compartimiento diferencial entre hombres y mujeres (Rimè et al 1996)

¿Se comparte por igual en todos los países? No, es obvio que no. Un estudio, realizado en 1996 por Rimé, Yogo y Pennebaker en que se estudiaron cinco países (EE. UU, Francia, Korea, Singapur y Japón), demostró que el mayor grado de compartimiento se da en Estados Unidos y Francia, mientras que es mucho menor en las sociedades orientales. En países como Japón y, especialmente, Singapur y Korea, las diferencias son muy significativas, incluso cuando estudiamos el tiempo la latencia del compartimiento, esto es, el tiempo que tardan en compartir desde que ocurrió el acontecimiento. En estas sociedades se tarda mucho más tiempo que en EE. UU o Francia. Así, por ejemplo, mientras que en los EE. UU. se tarda una media de día y medio en compartir, en Singapur la media es de más de cuatro días y medio. Estas diferencias son atribuibles a las formas en que cada sociedad regula qué, cómo y cuando se comparten las emociones, fruto de los procesos de socialización y educación.

Tiene para nosotros un especial interés el estudio de la dinámica de este proceso. Una hipótesis para explicarlo sostiene que el compartimiento se realiza inicialmente porque cuando necesitamos compartir, el interlocutor manifiesta interés. Imagínense ustedes que desean compartir y la otra persona les dice: "verás, ahora no puedo atenderte, dímelo rápido, porque tengo mucha prisa, si quieres hablamos otro día ". En este caso el compartimiento no se lleva a cabo. De tal manera que el interés es una condición indispensable para que se produzca ese proceso, y ese interés va a suscitar empatía, esto es, quien comparte (A) siente que el interlocutor (B) será capaz de entenderlo y compartir sus sentimientos. A su vez, el receptor (B) va a dar 
soporte a A, haciéndole sentir acompañado y comprendido. Todo esto produce un efecto beneficioso muy simple: cuando hablamos con alguien que para nosotros es importante y le comentamos una situación emocional, este hecho nos produce alivio, nos hace sentir bien. Como ven, este proceso explicaría que ambos sujetos están siguiendo un proceso en que ambos interactúan dinámicamente; si bien $\mathrm{A}$ emite y $B$ recibe la información, durante el proceso está también implicada la expresión de las emociones y sentimientos de ambos aunque, lógicamente, con la distancia que da el que el sujeto A es quien vivió la experiencia, mientras que el sujeto $B$ la está recibiendo (y emitiendo también una respuesta emocional atenuada por la lógica distancia con el suceso) (Figura 12).

Imagínense que nos dan una noticia relacionada con el estado de salud de un familiar cercano, y nos comunican que está en estado comatoso y que muy probablemente morirá, porque ha sufrido un accidente cerebrovascular. Lógicamente nosotros responderemos dando una respuesta emocional intensa, inicialmente de sorpresa y, casi instantáneamente, de tristeza. Nuestro cuerpo reaccionará inmediatamente provocando una intensa activación fisiológica: sentiremos que el corazón late con más rapidez, la respiración se hace, también, más intensa; posiblemente nos suden las manos y todo nuestro cuerpo se ponga en tensión. Habrán supuesto que necesitaremos compartir inmediatamente esta noticia. Durante el proceso de compartimiento reviviremos con intensidad (menor que durante el episodio original en que nos comunicaron la noticia) las emociones que sentimos para, instantes después sentirnos mejor. Este efecto es bien conocido, seguro que todos ustedes se han dicho así mismos: "iqué peso me he quitado de encima!" cuando han expresado algo que querían contar a otro, y especialmente cuando lo habían silenciado y reprimido durante mucho tiempo.

Experimentamos la sensación de alivio porque, en realidad, lo que ha sucedido es que nuestro cuerpo se ha desactivado, reduciendo la activación fisiológica y el malestar asociado a este estado. En otras palabras: quien expresa, siente alivio al compartir. Pero no olvidemos que en este proceso de interacción hay también otro sujeto más: el interlocutor al que hemos hecho partícipe de nuestro estado emocional.

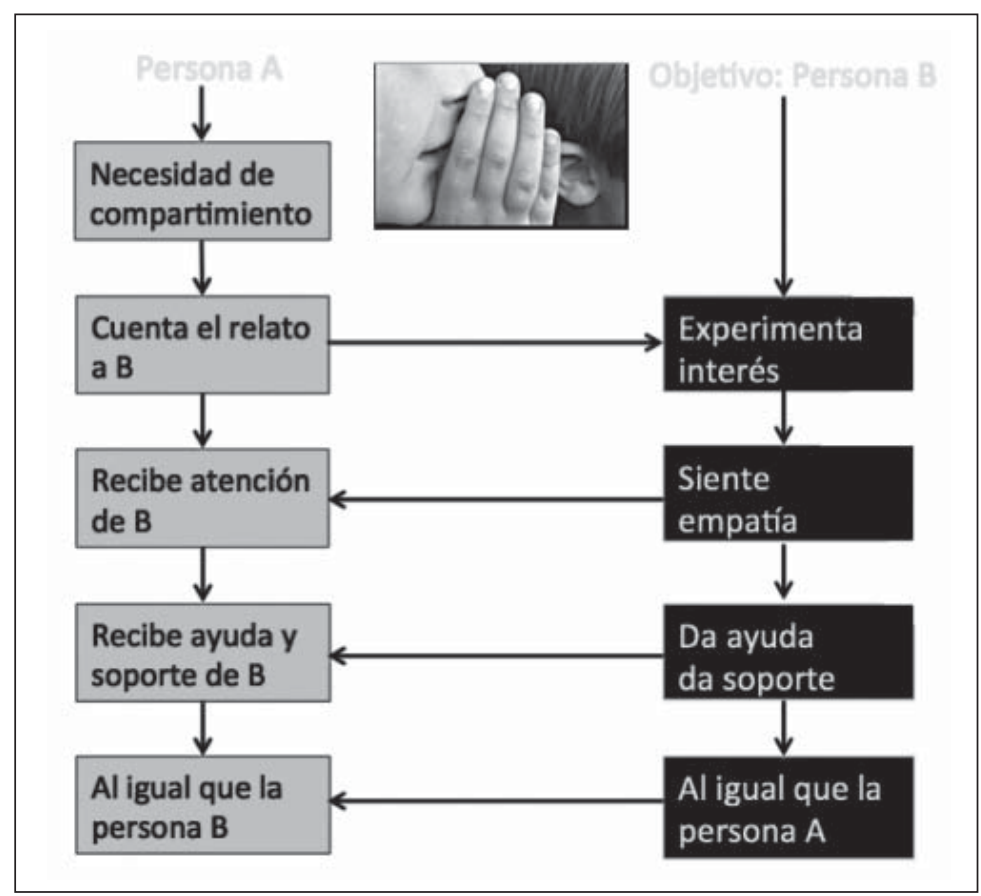

Figura 12. Dinámica del proceso de compartimiento 
El resultado es que a éste le hemos inducido indirectamente un estado de activación, como fruto del proceso de compartimiento. ¿Cómo creen que se desactivará el interlocutor?, si, así es: compartiendo nuevamente el suceso con un nuevo sujeto (compartimiento de orden secundario). Ya saben cómo sigue el proceso: al compartirlo reducirá la activación y, a su vez, inducirá malestar al nuevo interlocutor, y el proceso continúa. Lógicamente los compartimientos de orden secundario y terciario son, progresivamente, menos intensos porque cada vez hay mayor distancia con el hecho original que causo el compartimiento y la distancia afectiva entre los actores es, paulatinamente, mayor $\mathrm{y}$, por tanto, induce un menor interés y una menor implicación afectiva hasta que el proceso de detiene.

Posiblemente el acontecimiento más traumático que ha vivido mi país, España, en las últimas décadas sea el atentado islamista que sufrió la ciudad de Madrid el 11 de marzo del 2004. Seguro que ustedes lo recuerdan y también lo vivieron, con la misma intensidad que nosotros.

Recordarán que murieron 191 personas y resultaron heridas 1.858. Mucha gente viajaba en esos trenes, y el nivel de afectación que produjo en la población fue muy alto, ya no sólo en los directamente implicados, sino también en toda España: todos fuimos víctimas del cruel atentado perpetrado por radicales islamistas. Este hecho nos sirvió para estudiar cómo la gente compartió socialmente sus emociones en respuesta al atentado. Inicialmente toda la población, y especialmente en la ciudad de Madrid, los servicios de atención social, hospitales, bomberos, policía, dieron una respuesta ejemplar. La gente acudió masivamente a los hospitales para donar sangre, los psicólogos se presentaron voluntarios para atender a los miles de familiares de muertos y heridos, algunos de ellos eran alumnos y compañeros míos. El impacto emocional fue muy similar al que comentamos al inicio de esta conferencia cuando hablamos del terremoto de San Francisco.

El mismo día del atentado, profesores de varias universidades españolas nos propusimos estudiar los efectos del atentado, valorando cuál era la reacción de las personas, tanto las afectadas directamente como de quienes no lo sufrieron personalmente. Para ello entrevista- mos a más de 1.800 personas de toda España en tres ocasiones: el 25 de marzo, el 25 de abril y el 25 de mayo de 2004 .

Tras el impacto inicial, los resultados mostraron que progresivamente la gente hablaba con menos frecuencia del acontecimiento; dos meses después, el número de personas con las que compartían y el número de veces que hablaban del tema se redujo siguiendo el patrón que ya habíamos visto anteriormente. Si inicialmente la media de personas con la que habían hablado del atentado en los últimos 15 días era de 20 , dos meses después la cifra se reduce a sólo 3 personas. Del mismo modo, el número de síntomas asociados al malestar emocional se reduce paulatina y paralelamente a la reducción del compartimiento. Estos síntomas están asociados al trastorno por estrés post-traumático, una grave alteración que ocasiona un malestar emocional muy intenso, incapacitante en muchísimos casos.

En comparación con las consecuencias del atentado que se produjo en Nueva York el 11 de Septiembre de 2001, los estudios epidemiológicos señalan que las consecuencias en Nueva York fueron mayores, no sólo porque el número de muertos fue mucho mayor, sino también porque España ha convivido durante décadas con el terrorismo de la ETA; además, para los EE. UU. este atentado puso de manifiesto en la sociedad estadounidense su vulnerabilidad al terrorismo al que, desgraciadamente, tan acostumbrados estamos en España. El atentado de Madrid produjo trastornos por estrés pos-traumático a más de 40 mil personas, en una ciudad de más tres millones y medio de habitantes.

Nuestros datos demostraron que la recuperación del malestar emocional estuvo asociada a la disminución del grado de compartimiento. El distanciamiento con el hecho traumático es una estrategia exitosa para recuperarse del malestar emocional. Ésta es una estrategia de afrontamiento que todos empleamos: nos distanciamos del suceso para sentirnos mejor, pensamos en otra cosa, evitamos hablar de él, etc. Más tarde hicimos un nuevo estudio en que queríamos valorar la hipótesis que sostiene que quienes, transcurridos meses desde el atentado, seguían compartiendo su estado emocional con los demás, hablando del suceso, participando en reuniones, manifestaciones y otros actos, se 
recuperarían más tarde y arrastrarían durante más tiempo las consecuencias del atentado. En otras palabras: nos interesaba verificar si, por ejemplo, transcurrido mucho tiempo, pongamos más de un año desde que sucedió el acontecimiento emocional traumático, sigo hablando de él con la misma frecuencia e intensidad que si hubiera ocurrido hace 2 días, esto produciría efectos negativos en el sujeto. La hipótesis de la cual nosotros partíamos sostenía que quienes más habían hablado (compartido), participado en manifestaciones, reuniones, adhesiones en actos, etc., 4 meses después del atentado, se habrían recuperado peor del trauma causado tras el 11 de marzo, que quienes paulatinamente dejaron de compartir sus emociones (Figuras 13 y 14).

Los resultados que obtuvimos demostraron que el nivel de recuperación fue significativamente menor para aquellas personas que, lejos de distanciarse del suceso, lo revivían con mucha frecuencia, compartiéndolo socialmente más allá del lo que consideramos adaptativo. Estos resultados nos permiten concluir que rememorar, compartir, hablar, etc. sobre un acontecimiento emocional, transcurrido un tiempo necesario para la adaptación, lejos de contribuir a su superación, se convierte en un problema en sí, dificultando la recuperación del sujeto y prolongando el malestar emocional durante meses y, en algunos casos, años. Estos resultados deberían ser tenidos en cuenta por cada uno de nosotros, sino también por los estados. Todos los países han vivido etapas convulsas en las que se cometieron muchas atrocidades; revivirlas, compartirlas, reabrirlas constantemente estos acontecimientos, que tanto dolor causaron, lejos de contribuir a su superación, producen un efecto contrario, es decir, perpetúan el problema reavivando constantemente el malestar emocional, enfrentando
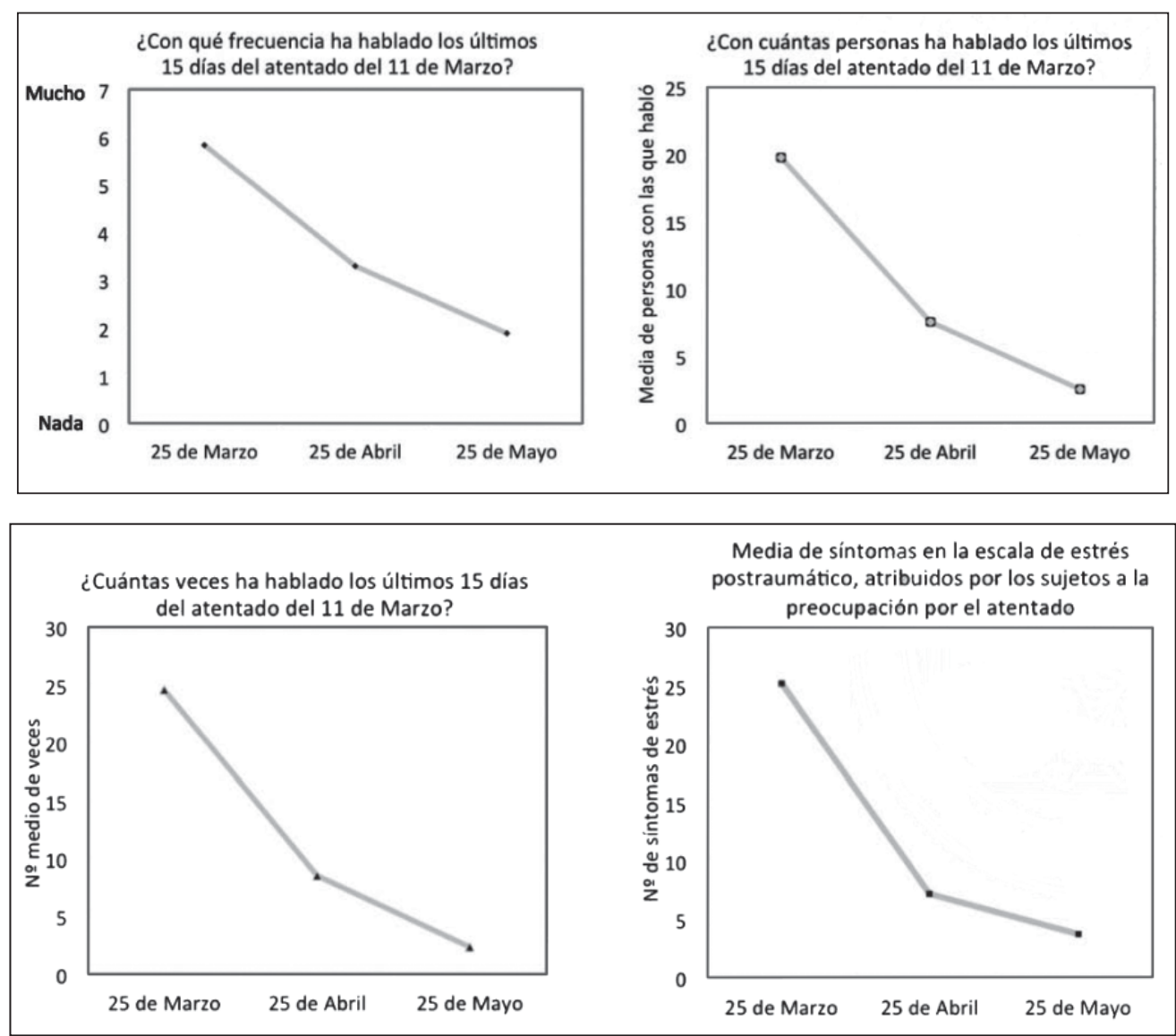

Figuras 13 y 14. Evolución del compartimiento social de la emoción en respuesta al atentado del 11 de Marzo de 2004 en Madrid (Paez, Martínez Sánchez y Rimè, 2004) 
a los ciudadanos y obstaculizando la concordia y la convivencia futura de los ciudadanos de un país. Mi país, España, y sospecho que también el suyo, Uruguay, deberían tomar buena nota de estos resultados.

Por último, permítanme que resuma muy brevemente lo que he tratado de trasmitirles en esta conferencia: tras sentir una emoción, la gente, de manera inmediata y recurrente habla de ella, preferentemente con personas cercanas y poco tiempo después de suceder. Éste es un fenómeno universal, que se produce en respuesta a la mayoría de los sucesos emocionales que vivimos, independientemente de la edad, el sexo, la cultura e incluso, del tipo de emoción que hayamos sentido. Además, cuanto más intensa es esa emoción, en mayor medida la compartimos.
Cuando una persona ha superado un acontecimiento emocional, normalmente no tiene la necesidad de hablar de él, por ello, compartir las emociones intensas y recurrentemente más allá de un tiempo adaptativo, lejos de contribuir a la superación de las consecuencias de sucesos traumáticos, los perpetúa en el tiempo, dificultando su superación.

Muchas gracias a todos por su atención.

1 (N. de la Ed.). Conferencia dictada por el Dr. Francisco Martínez Sánchez el 17 de mayo de 2011 en el marco de las actividades de los programas de Doctorado en Psicología y del Postgrado de especialización en Psicología Clínica, orientación Psicología Cognitiva (revisada por el autor). . Invitado por el Departamento de Teorías Psicológicas y Psicología Clínica, de la Facultad de Psicología de la Universidad Católica del Uruguay.

Para citar este artículo:

Martínez Sánchez, F. (2011). El uso compartido de la emoción: ¿porqué necesitamos compartir las emociones? Ciencias Psicológicas V (2): 201-212. 